\title{
Healing and Hope Transforming Nursing Care: A Commentary
}

\author{
The Contribution to Healing and Hope Derived from Different Views of Humanity and \\ Nursing Practice \\ Professor Emeritus Barbara Ann Parfitt CBE PhD RM RN FNP ALBC*
}

Glasgow Caledonian University, Cowcaddens Road, Glasgow G2 OBA, UK

\begin{abstract}
*Corresponding Author: Professor Emeritus Barbara Ann Parfitt, Glasgow Caledonian University, Cowcaddens Road, Glasgow G2 OBA,UK, Email: Barbara.Parfitt@gcu.ac.uk
\end{abstract}

\begin{abstract}
This commentary reflects on the nature of holistic nursing care as expressed through the values of the nurse or care provider. It explores the different underlying beliefs of caring from three value systems, faith, humanism and biological or scientific. It does not claim that these value systems are necessarily complete in themselves but it does suggest that in order to provide Holistic care the nurse or carer needs to understand all of the values that drive their practice. The commentary goes on to discuss the importance of hope in the healing process claiming that hope is an essential requirement for true healing to take place. In summary the commentary states that nurses and carers are responsible for bringing hope and healing to those they care for.
\end{abstract}

Keywords: Holism, Hope, Healing, Humanism, Faith, biological, Nurse, Values, Nursing

\section{INTRODUCTION}

In this commentary I want to share with you an understanding of the critical nature of the values that nurses hold and their impact on the practice that they perform. I hope I will be able to show you that healing is much more than recovery and that hope is much more than the avoidance of despair. Research has shown that there is a direct link between the values held by the carer and the experience of those being cared for [1][2] [3]

When I was a student nurse I remember clearly a patient dying on my first ward. The ward sister pointed out that he didn't need to die but that he had 'given up'. She went on to say 'healing is always a joint effort and if the patient gives up then our task is almost impossible'. I didn't think then to ask what we should do to help this person but later I thought about what it must mean to have no hope. As a young person I could not imagine what that could be like and I realised that I didn't know how to help someone in that situation and nursing, as it was taught then, gave little time to caring for the soul and emotional involvement was strictly forbidden.

The majority of us have to work within health systems that are organised largely according to medically defined norms and while we may prefer as individuals to express our care through more humanistic and holistic structures the reality is we are often constrained by the systems within which we work. The context in which many of us care for our patients will vary but where ever that is, for healing to take place, their must be hope and for hope to exist there has to be caring practice that believes in the intrinsic value of humanity.

I would like to briefly look at the kind of values and practice that emerge within three different models of care, faith, humanistic and biological scientific or medical.

To some extent these labels stereotype different schools of thought and rarely is life so easy that we can define it in this way, more commonly individuals overlap their world views. But for my purpose this differentiation between the different philosophical approaches will help us understand the influences that impinge on the way we prioritise the care we give and the importance that we place on certain caring activities.

\section{A Faith VieW OF HUMANity}

I will start with a faith view of humanity. Religions differ in many ways but there are common principles that they all share. Within many faiths the person is primarily seen as a spiritual being. Faiths acknowledge that there is a spiritual dimension to our nature, which 
focuses the ultimate purpose of our existence towards God. Religions differ in how the relationship with God asserts itself but fundamentally they share this common desire [4]. Religions identify spirituality as something that cannot be separated from the whole person. Spirituality embraces the world in its fullness and that includes suffering and pain as well as joy and hope [5]. Worth cannot be attributed to social status, gender, race or colour. The unique significance about each person is their individuality. That individuality is framed within personal dignity and value. Human dignity is central to a faith understanding of mankind. A significant part of the task of the nurse, doctor or carer who works within a faith model is to enable people to discover their own spirituality, to create the context and space where healing relationships can be built up and an individual can begin to experience hope knowing they are truly human, loved and cared for by God in whatever form that takes.

\section{Health and Suffering From a Faith PERSPECTIVE}

Patients often see illness and suffering as a direct consequence of their sin. God's punishment! How often do we hear someone say "What have I done to deserve this? This view is contrary to Islamic, Christian and the Judaist view of sin and also many other religions, but the belief that human beings are separated from God through sin has important implications for the ways in which patients and carers with faith deal with the illness experience and the meanings that they place on it. As a result caring in whatever form it takes is by nature deeply theological. This is because it helps people to deal with their illness and discover their innate spirituality. It helps them to recognise that illness and suffering are not the consequence of personal failure. The values that underpin this approach are those of justice, equality and tolerance, of caring love that demonstrates compassion and self-respect. For the faith carer the primary focus of care is to create an environment that allows forgiveness and healing.

\section{The Humanistic VieW OF Humanity}

Humanism focuses on human dignity and the creative powers of human beings, and a humanistic understanding of humanity emphasises the importance of the individual. The centrality of the individuals' own potentiality to achieve dignity, to strive for goodness or greatness and to seek to live up to what the individual is capable of [6]. Hope is the very essence of the humanistic tradition, a hope that relies upon the power of the self.

Humanism involves the human experience including self-confidence, endurance, nobility, love, intelligence, sympathy and courage to rise above a sense of incompetence and despair.

Modern humanism upholds the dignity of human beings and recognises that every human being has self-value. This respect for human dignity is the real ground for human rights. It also identifies the intrinsic power of human beings to be creative and self-reflective. It emphasises that we can never be reduced to numbers or anonymous classifications and that we all have a 'spiritual' dimension which is part of our intrinsic selves but not religious.

\section{Health AND SUfFERING FROM A HUMANisTiC POINT OF VIEW}

Humanism recognises the individual's capacity for self-fulfilment supporting a full and active life. Health is obtained through the ability of individuals to meet the demands made on them in different circumstances. The role of the nurse is to enable the individual to set their own goals and outcomes during care and with support from the nurse to achieve them [7].

The values that underpin the humanistic tradition are those that reinforce the notion of empowering the self and creating one's own life. The humanistic tradition focuses on inner development and freedom to make individual choices. This emphasis on the importance of the individual means there is also great importance placed on relationships with others. There is recognition that we all require sympathy and support and that we should be prepared to give it to each other. Healing is accomplished through the recognition and confirmation of the worth of the individual.

\section{The Medical, Natural or Scientific VIEW}

The natural, medical or biological view of humanity considers the human as biological. Biological normality and abnormality are described in functional, statistical and epidemiological terms with a focus on regularity, law and generalisation. The two goals of medicine that are common to all organisms are survival and reproduction. The real threat to biological beings is disease which threatens the normal functioning of the organs. Human dignity may therefore in a natural way 
be understood as the optimal functioning of the organs without abnormalities and pathologies. Diseases may be interpreted as defects that influence the integrity of the person and his or her dignity as a human being.

This disease based health model uses bio statistical theory to define levels of normality. The bio statistical health disease continuum determines the degree of personal health of the individual. In this conception of health it is impossible to understand that a person may have ill-health without organic disease or good health in spite of living with chronic disease. The disease is the primary focus and is the key component in thinking of health. Medical knowledge is concentrated on the development of new methods for the examination and treatment of disease.

The values that underpin this medical, natural approach are based on survival and reproduction these demonstrated through statistical normality as overall values. The facilitation of treatment and prevention of diseases in the body become the main healing activities, care becomes legalistic limited by its need to be evidence based through quantitative data.

\section{HEALTH AND SUFFERING FROM A Medical or Biological Point OF VieW}

The prioritising goals for medicine are the prevention of disease and injury and the promotion and maintenance of health, the relief of pain and suffering caused by disease and illhealth, the care and cure of those afflicted and the care of those who cannot be cured and finally the avoidance of a premature death and the pursuit of a peaceful death. The major short comings in this approach is at a personal level as primarily the individual can be forgotten and ceases to have value. The philosopher Toombs [8], who had multiple sclerosis stated that 'curing is a function limited to disease while healing goes beyond disease to the person'.

\section{HoPE AND HEALING}

When reviewing the three models of care presented above it is apparent that no single approach will provide holistic care. The focus of healing in the faith approach is healing relationships, the humanistic approach focuses on restoring and maintaining the self while the medical model sees healing as repair of the body. For healing to take place we must include all of these dimensions, no one is complete in itself.
But what of hope, how is it related to healing?

Hope is described in many ways by different people. It is associated with meaning and purpose, with having life goals with a belief in the opportunities and possibilities of the future. Hope is described as a dynamic process, it is not static and it may not be permanent. Hope or the lack of it affects our emotions. There is a dialectical relationship between hope and despair, a relationship that reflects our emotional experience. We may have feelings of security and peace as a result of having hope while a loss of hope will give rise to feelings of insecurity and grief. Hope also gives us a sense of purpose, it allows us to set goals, it creates an active environment, it impacts upon the way we think, the way we behave, our relationships with other people and also influences our spiritual well-being.

I would like now to go back to the story that I told you at the start of the presentation. The man who had given up. Who according to the ward sister was willing his own death because as she said we are all responsible for $50 \%$ of our recovery and if we give up then medicine cannot help.

This man had lost the meaning of his life; he had no hope and no healing. The sadness here was that there was no expectation that we could help. There was no recognition that he might be supported. I knew that I had no training or guidance to help him. His needs went beyond the physical, the mental and the social and they may have been spiritual. Spiritual needs are expressed when we have lost hope, our lives have no meaning and the consequences are that healing cannot take place.

It is unlikely that any one of us uses a single model for our practice. We are driven by many different forces and the values that underpin the care we give beyond the model of care we utilise. Yet there is no doubt that the over emphasis on the medical model has led to a depersonalisation of care in modern practice. Nurses and doctors are accused of no longer taking an interest in their patients. Nurses are consumed by the demands of technical care. Healing is not the priority. Hope is not recognised as a need. Our dilemma is how we express the holistic and relational parameters of care.

It is our values and beliefs that underpin our motivation and moral awareness. These values 
and beliefs will influence what we regard as most important in our professional practice.

Good caring does not imply that we can remove all pain or suffering for our patients. Rather in real life situations good caring creates optimal chances for the patient to have hope. Good caring always implies hope. Good caring is a healing process. It is a means to help others to endure their suffering.

\section{SUMMARY}

Hope and healing are expressed through many different understandings of humanity. These understandings give rise to different priorities in practice. Nurses can use a number of different nursing models many of which will emphasise different priorities reflected in these three value sets. The focus of the faith model is healing relationships, the medical / biological model emphasises repair of the body while the humanistic model focuses on restoring and maintaining the self. Hope and healing are evident in all of them and yet without each dimension it is impossible to say if the care is holistic. The beliefs and values of both patients and carers will influence the care given and a denial of any of these dimensions will in turn deny the patient a holistic caring experience.

What might I do today to meet the needs of the man who was dying? I am not entirely sure but I certainly could not have left him alone. Giving up is not the same as acceptance. The latter is positive. If the carer gives up what hope has the patient or the person being cared for? Not giving up does not mean believing the impossible or refusing to believe the inevitable. Not giving up is to have hope and to have hope is to promote healing.

If we are to provide care that is Holistic we need to nurture our spirituality, our relationship with ourselves and other people and our understanding of the biological realities that face our patients. Our values will influence the priorities that we set and even within the rigid parameters of medically defined health services there is space for love, compassion and healing to take place. Hope can exist in the darkest of places and as true carers our responsibility is to bring hope and healing to those we care for.

\section{REFERENCES}

[1] Kylma J,.Juvakka T,.Hope in Adolescents with Cancer- Factors Endangering and Engendering Parental Hope, European Journal of Oncology Nursing 11 3. pp262-271 (2007)

[2] Pullen R LJnr,.Mathias T,. Fostering the rapeutic nurse patient relationships, Nursing Made Easy, Wolters Kluter Vol 8 Issue 3 P4 May /June (2010) doi: 10.1097/01.NME.0000 371036.87494 .11

[3] Clark C S,. Watsons Human Caring Theory: Pertinent Transpersonal and Humanities Concepts for Educators, Humanities www. mdpi.com/journal/humanities 5,21 doi:10.3390/ h5020021 (2016)

[4] Umar F Abd-Allah,. The Perceptible and the Unseen: the Qur'anic Conception of Man's Relationship to God and Realities beyond Human Perception , IN Mormons and Muslims; Spiritual Foundations and Modern Manifestations, ed. Spencer L. Palmer Provo, UT Religious Studies Center, Brigham Young University , 209-64(2002)

[5] Ryle J C,. Holiness, Hertfordshire, England, Evangelical Press (1979)

[6] SkorupskiJ,. The Cambridge Companion to Mill, Cambridge University Press (1997)

[7] Hu Li ZaZhi,. The Spirit of Humanism Should be Cultivated in the Nursing Profession, Journal of Nursing, Pubmed, PMID: 22024799 [Indexed for MEDLINE] Oct;58(5):12-6 (2011)

[8] Toombs S K,. The meaning of illness Dordrecht: Kluwer Academic publishers(1993)

Citation: Professor Emeritus Barbara Ann Parfitt. Healing and Hope Transforming Nursing Care: A Commentary. ARC Journal of Nursing and Healthcare. 2017; 3(2):5-8. doi: dx.doi.org/ 10.20431/24554324.0302002.

Copyright: (C) 2017 Authors. This is an open-access article distributed under the terms of the Creative Commons Attribution License, which permits unrestricted use, distribution, and reproduction in any medium, provided the original author and source are credited. 